\title{
The Classroom Information Manual: A Guide to the Teaching Environment
}

\section{Marina Estabrook}

Most courses offered by colleges and universities are housed in what are called general assignment classrooms. Although much similarity exists among classrooms they are not all alike nor do they serve all instructional purposes equally well. Therefore to provide instructors with information about campus classrooms can greatly assist them with their teaching.

The development of the Classroom Information Manual was inspired by a faculty evaluation study of classrooms conducted on our campus (Estabrook, 1981). We learned from the study that an important source of faculty dissatisfaction with classrooms is a poor match between instructor and classroom. For example, some mathematics and engineering professors in need of large blackboard space taught in classrooms with small blackboards; geography and history instructors who use maps for demonstration purposes taught in classrooms with no wall map hooks; instructors who wanted to stimulate discussion among students taught in classroom with fixed as opposed to movable furniture; instructors using slide demonstrations taught in classrooms ill-suited for slide projection.

We also learned from our study that a lack of familiarity with the classroom prior to the commencement of instruction can cause the instructor unnecessary frustration and confusion. For instance, in some lecture halls on our campus the electric outlets for projection are hidden under student seats; some classrooms require extension cords 
or special lenses for projection purposes; some light and sound control panels have a baffling array of switches and plugs.

Finally, our study informed us that faculty and department staff lack information about whom to contact in case problems or questions arise with respect to classrooms. Faculty endured such inconveniences as lack of chalk and erasers, no lecterns, no projector stands, no instructor's desk or chair, flickering lights, broken rheostats, faulty PA systems, broken screen strings, unreachable venetian blind ropes, etc.

The classroom study thus helped us to formulate the objectives of the Manual and to identify what information about classrooms would be useful to instructors.

\section{The Classroom Information Manual}

The Manual contains a description of each general assignment classroom. The sample classroom description below identifies the salient classroom features.

\section{Description:}

Maximum seating capacity: 306

Shape: nearly square (55' $x$ 45')

Windows: along one side are windows that open

Covering: drapes

Doors: one in front and one in rear

Special feature: clock

Blackboard space: one wall (24'); blackboard lights

Student seating: $\mathbf{3 0 0}$ fixed desks; writing arm is small in size; seats are numbered; floor is tiered and partially carpeted

Instructor's area: fixed lab table; lectern

A/V capabilities: projection booth and cabinet; built-in remote control and built-in PA system; electrically controlled screen in front; electric outlets in front, back and in projection booth; darkening capabilities are good; light control in front; partial lighting capabilities. 
Comment: the PA and projector systems cannot operate simultaneously.

In addition to the descriptions, we listed classrooms according to classroom features. Thus users of the Manual can quickly determine which rooms have TV monitors, rheostats, windows that open, fixed seating, etc. Furthermore, we listed whom to call on campus concerning classroom matters.

The Manual was distributed to all departments on campus with a cover letter outlining its objectives: (1) to assist departments with special teaching needs in requesting room assignments; (2) to familiarize faculty members with the classrooms in which they are scheduled to teach; (3) to inform departments who on campus offers assistance on classroom matters.

\section{Follow-up}

A year after the Manual was distributed we asked the principal users in each department to evaluate the content of the Manual and its usefulness. We sent 46 questionnaires and received 26 replies (56\%).

We learned that the principal users of the Manual were department administrative assistants whose responsibilities include arranging room assignments for department courses and scheduling rooms for colloquia, seminars, and conferences. Faculty use of the Manual varied among departments. In one-third of the departments 20\%-25\% of the faculty had used the Manual. I the remaining two-thirds of the departments, less than $10 \%$ of the faculty had used it.

The evaluation of the Manual by its principal users has been very favorable. For the purpose of requesting room assignments for department courses, $68 \%$ of the respondents found it very useful; $27 \%$ somewhat useful; $4 \%$, not useful at all. For scheduling conferences, colloquia, or seminars, $80 \%$ found it very useful; $10 \%$, somewhat useful; $10 \%$ not useful at all.

Faculty members have also reacted favorably to the Manual. The Manual not only helped faculty members locate classrooms more suitable for their teaching purposes than the one in which they usually taught, but it also increased faculty awareness of the teaching environment. One instructor who paces and likes to maintain eye contact with 
students found that he is far more comfortable teaching in a wide and shallow room than in a long and narrow one. Another instructor has developed a new approach toward slide presentation after learning that there are classrooms with double screens.

Overall, our experience with the Manual has convinced us that such a document is a useful instructional resource. 